\title{
Revisitando a escola inglesa - da velha via média das relações internacionais à nova escola inglesa
}

\author{
Raquel de Caria Patrício ${ }^{1}$ \\ Professora no Instituto Superior de Ciências Sociais e Políticas \\ Universidade de Lisboa \\ raquelpatricio@iscsp.ulisboa.pt
}

Como citar este artigo: PATRICIO, R. "Revisitando a escola inglesa - da velha via média das relações internacionais à nova escola inglesa", Intelligere, Revista de História Intelectual, nº10, pp. 140-161. 2020. Disponível em $<$ http://revistas.usp.br/revistaintelligere $>$. Acesso em dd/mm/aaaa-

Resumo: Este capítulo procura posicionar a Escola Inglesa na via intermédia entre o Realismo e o Idealismo, focando-se no pensamento de Hedley Bull e Martin Wight, e analisar a evolução da Escola Inglesa após o derrube do muro de Berlim, quando novas problemáticas foram agregadas ao estudo da sociedade internacional e das instituições internacionais. Pretende-se ainda demonstrar como a Escola Inglesa, fundada nas normas e nos padrões regulares de comportamento, é uma grande influência para a abordagem construtivista. Frente a estas realidades, surge a grande pergunta de partida: por que razão, apesar dos estudos de Hedley Bull e de Martin Wight sobre a sociedade internacional e as instituições internacionais, a Escola Inglesa se manteve, à época, marginalizada frente à Escola Norte-Americana de Relações Internacionais? a qual origina objetivos, alguns dos quais já mencionados, e hipóteses de trabalho, que serão alcançados e comprovadas.

Palavras-chave: Escola Inglesa, sociedade internacional, instituições internacionais, Hedley Bull, Martin Wight, Nova Escola Inglesa.

1 Doutora em Relações Internacionais pelo Instituto de Relações Internacionais da Universidade de Brasília (2005). Professora no Instituto Superior de Ciências Sociais e Políticas (Universidade de Lisboa) desde 2007. Áreas de Pesquisa: Estudos Latinoamericanos, Política Externa Brasileira, União Europeia, Teoria das Relações Internacionais.

Email: raquelpatricio@iscsp.ulisboa.pt ORCID ID: http://orcid.org/0000-0001-8630-0677. 
Revisiting the English school - from the old middle way of international relations to the new English school

Abstract: This chapter intends to position the English School between the middle ground between Realism and Idealism, focusing on the thought of Hedley Bull and Martin Wight, as well as analyzing the evolution of the English School after the fall of the Berlin Wall, when new issues were added to the study of international society and international institutions. It is also intended to demonstrate how the English School, founded on norms and regular patterns of behavior, is of great influence for the constructivist approach. Faced with these realities, the big question arises: why, despite the studies by Hedley Bull and Martin Wight on international society and international institutions, the English School remained, at the time, marginalized in face of the North American School of International Relations? This gives rise to objectives, some of which have already been mentioned, and working hypotheses, which will be achieved and proven throughout this chapter.

Keywords: English School, international society, international institutions, Hedley Bull, Martin Wight, New English School

\section{Introdução}

Procurando fugir à hegemonia das Escolas norte-americanas de Relações Internacionais, Franceses e Britânicos vieram propor, com especial ênfase a partir da década de 1960, terceiras vias, alternativas, quer aos extremos do debate metateórico entre Realistas e Idealistas, quer ao debate metodológico, também extremado, entre Realistas e Behavioristas.

Neste sentido, procurar-se-á, com este capítulo, deixar claro o posicionamento de Hedley Bull e de Martin Wight - autores-chave da Escola Inglesa - nesta terceira via, transpondo aquilo que são as coincidências e as divergências do pensamento internacionalista de cada um, particularmente ao redor da grande herança da Escola Inglesa: o conceito de sociedade internacional, agregado ao conceito de instituições internacionais. Uma vez expostas estas ideias centrais, torna-se interessante avaliar a evolução da própria Escola Inglesa, que esteve em período de decadência nas décadas de 1980 e 1990, e analisar como e em torno de que problemáticas se erige a Nova Escola Inglesa. Afinal, se a sociedade internacional e as instituições internacionais continuam a serem conceitos fundamentais em torno dos quais 
gira a Escola Inglesa renovada, outros processos se agregam aos seus estudos, enriquecendo-os e tornando mais robustas as próprias análises sobre a sociedade internacional e as instituições internacionais, que ganham uma nova dinâmica, incluindo a da regionalização da sociedade internacional. Torna-se ainda interessante verificar como a Escola Inglesa, ao fundar-se nas normas e padrões regulares de comportamento, pode ser considerada uma precursora ou grande influenciadora das abordagens, que já então se faziam, mas totalmente marginalizadas, do Construtivismo.

Neste âmbito, a pergunta de partida deste capítulo, que guiará toda a investigação, é: por que razão, apesar dos estudos de Hedley Bull e de Martin Wight sobre a sociedade internacional e as instituições internacionais, a Escola Inglesa se manteve, à época, marginalizada frente à Escola Norte-Americana de Relações Internacionais?

Para dar resposta a esta pergunta de partida, diversos objetivos se colocam, para além dos enunciados acima. Desde logo, ter-se-á por objetivo avaliar as novas perspetivas e instituições, sua hierarquização, mudança e evolução, por parte da Nova Escola Inglesa. De seguida, procurar-se-ão distinguir as novas funções e o conceito de regionalização da sociedade internacional propostos pela Nova Escola Inglesa, para finalmente avaliar-se se a Escola Inglesa está na base do pensamento do Construtivismo aplicado às Relações Internacionais.

Diretamente relacionadas aos objetivos, surgem as hipóteses de trabalho desta pesquisa, sendo certo que, frente aos objetivos, podemos dividilas em três:

- A Nova Escola Inglesa apresenta novas perspetivas e instituições internacionais, acrescentadas de estudos sobre a sua hierarquização, mudança e evolução;

- A Nova Escola Inglesa distingue novas funções para a sociedade internacional e propõe, com êxito, a sua regionalização;

- A Escola Inglesa, em função dos seus fundamentos teóricos, está na base do pensamento construtivista aplicado às Relações Internacionais. 
Vale notar que a Escola Inglesa se apresenta com esta designação porque, embora muitos dos acadêmicos que, durante os anos de formação da Escola, não fossem ingleses, a maioria trabalhava em Inglaterra, especialmente na London School of Economics e nas Universidades de Oxford e de Cambridge. Assim, foram particularmente Martin Wight (1913-1972), Hedley Bull (1932-1985) e Adam Watson (1930-...) que formaram a Escola Inglesa, embora também nomes como Richard Little (1938-...), R.J. Vincent (19431990), James Mayall, Robert Jackson e, mais recentemente, Barry Buzan (1946...), Tim Dunne e Nicholas J. Wheeler se dediquem aos estudos centrais da Escola Inglesa (BROWN \& AINLEY, 2009, p. 96), cuja história aparece muito bem documentada em Tim Dunne (DUNNE, 1998).

Assim sendo, este capítulo, após esta breve introdução, aborda um segundo ponto sobre a sociedade internacional e as instituições internacionais nos pensamentos de Bull e Wight. A estes pontos segue-se um terceiro e último sobre a Nova Escola Inglesa, finalizando este capítulo com as conclusões e as respetivas referências bibliográficas.

\section{A sociedade internacional $\mathrm{e}$ as instituições internacionais nos pensamentos de Hedley Bull e Martin Wight}

É neste sentido que, em A Política do Poder, de 1946, Martin Wight (1985 [1946]) trata da política entre os Estados, mas rejeita a política do poder de Morgenthau, já que rejeita os pressupostos realistas, embora não apresente uma alternativa utópica da política internacional. Se Wight não ataca o moralismo, também não apresenta lições práticas realistas, colocando a obra no centro do debate entre grocianos, kantianos e realistas e defendendo um meiotermo de ordem, numa abordagem normativista.

Marcada pelo normativismo de origem grociana, a Escola Inglesa considera que as relações internacionais decorrem em condições de anarquia, porém numa sociedade anárquica, na qual os Estados atuam no âmbito de um sistema de normas que se consideram moderadoras (BROWN \& AINLEY, 2009 , p. 97) e que são por eles criadas. 
Com efeito, num ambiente internacional onde não existe uma autoridade superior aos Estados soberanos, estes vivem em anarquia. Porém, o seu relacionamento é pautado por determinadas práticas recorrentes que compõem padrões legítimos de interação, as instituições, que são o elemento de ordem que confere ao sistema internacional a sua característica de sociedade internacional.

Na verdade, e segundo Hedley Bull (2002 [1977], p. 8), todas as sociedades procuram a ordem, mas a ordem procurada na vida social não é simplesmente um padrão de regularidade nas relações entre indivíduos ou grupos; é antes uma ordem que se caracteriza por ser "uma estrutura de conduta que leve a um resultado particular, um arranjo da vida social que promova determinadas metas ou valores". Neste sentido, todas as sociedades reconhecem ter, como objetivos gerais, "garantir que a vida seja protegida de alguma forma contra a violência", garantir que "as promessas feitas sejam cumpridas e que os acordos ajustados sejam implementados" e "garantir que a posse das coisas seja em certa medida estável, sem estar sujeita a desafios constantes e ilimitados" (BULL, 2002, p. 8).

Assim, a ordem na vida social surge, para Bull (2002, p. 13), como um "padrão de atividade humana que sustenta os seus objetivos elementares, primários ou universais", de onde resulta que a ordem internacional se refere a "um padrão de atividade que sustenta os objetivos elementares ou primários da sociedade de Estados ou sociedade internacional”.

Neste contexto, a sociedade internacional ou sociedade de Estados aparece, para Bull (2002, p. 19), quando "um grupo de Estados, conscientes de certos valores e interesses comuns, formam uma sociedade, no sentido de se considerarem ligados, no seu relacionamento, por um conjunto comum de regras e participam de instituições comuns", sendo certo que, por instituição, Bull (2002, p. 88) não pretende referir-se "necessariamente a uma organização ou mecanismo administrativo, mas a um conjunto de hábitos e práticas orientados para atingir objetivos comuns. Essas instituições não retiraram do Estado o seu papel principal de implementar as funções políticas da sociedade internacional, ou de substituir no sistema internacional a inexistente autoridade 
central". Para Bull (2002, p. 89), as instituições compõem o elemento de colaboração entre os Estados no desempenho da sua função política, constituindo ao mesmo tempo o meio para suportar essa colaboração. Ademais, as instituições simbolizam a existência da sociedade internacional, que representa mais do que a mera soma dos seus membros, conferindo substância e permanência à colaboração entre os Estados no exercício das funções políticas da sociedade internacional, moderando ainda a tendência dos Estados de perder de vista os seus interesses comuns.

Ao executar estas funções (BULL, 2002, pp. 85-88), os Estados colaboram entre si em vários níveis no âmbito das instituições da sociedade internacional que Bull (2002, p. 88) identifica como sendo cinco: o equilíbrio de poder, o Direito Internacional, os mecanismos diplomáticos, o sistema administrativo das grandes potências e a guerra.

Neste sentido, a existência de uma sociedade internacional pressupõe a existência prévia de um sistema internacional, embora um sistema internacional não seja necessariamente uma sociedade internacional. Afinal, os Estados podem interagir entre si sem que tenham consciência da existência, entre si, de interesses e valores comuns, estando apenas envolvidos num sistema internacional. Mas quando percebem que estão sujeitos a um conjunto de regras comuns e cooperam para o funcionamento das instituições comuns, então aí passam a estar envolvidos numa sociedade internacional (BULL, 2002, p. 88).

Deste conceito de sociedade internacional pode verificar-se que o estudo de Hedley Bull se centra sobre os Estados e não sobre outro tipo de atores, sejam eles entidades subestatais ou supraestatais. Por outro lado, é notório que a sociedade internacional e as instituições de Bull têm uma função ordenadora do internacional, que assenta na preservação do próprio sistema e da sociedade de Estados e no objetivo de manter a independência e a soberania externa dos Estados individuais (BULL, 2002, p. 23). É assim que se corporiza o conceito de ordem internacional de Hedley Bull.

Assim, as instituições de Bull estruturam-se na base da soberania como princípio ordenador da sociedade internacional, materializando regras de 
coexistência que enformam uma sociedade internacional mínima, pluralista, diversificada e evolutiva, diferente do que seria uma sociedade internacional solidária, assente num consenso mais abrangente sobre as regras de cooperação (BULL, 1966).

Efetivamente, para Bull (2002, p. 78), “as forças favoráveis à coesão social e à solidariedade são muito mais fortes nas sociedades anárquicas primitivas do que na sociedade internacional", já que a natureza menos exclusivista e menos interiorizada das unidades políticas que compõem as sociedades primitivas, a sua homogeneidade cultural e as suas crenças mágicas e religiosas compõem o substrato das suas regras. Logo, nessas sociedades, apesar da ausência de governo, existe um elevado grau de solidariedade social. $\mathrm{Na}$ sociedade internacional, a manutenção da ordem tem de funcionar, quer na ausência, permanente, desse governo, autoridade superior aos Estados, quer na ausência da solidariedade social. Nesta sociedade, a ordem é consequência, não só de factos contingentes como o sistema de equilíbrio de poder, a ausência de qualquer crença que sirva para embasar os interesses comuns, ou qualquer tentativa de regular ou institucionalizar o sistema internacional, mas também da existência de um sentido de interesses comuns nos objetivos mais elementares da vida social, da existência de regras que prescrevem a conduta dos Estados tendo esse objetivo em vista e da existência de instituições que ajudam a tornar efetivas essas regras (BULL, 2002, pp. 78-79).

Ora, ao vincular as instituições da sociedade internacional aos objetivos mais elementares dos Estados e às regras que prescrevem a ordem em qualquer sociedade, Bull estabelece uma perspetiva funcional sobre as instituições assente, não propriamente na análise histórica, mas numa teoria sociológica que ele próprio desenvolveu, no âmbito do classical approach da Escola Inglesa. As cinco instituições identificadas por Bull surgem, assim, não por serem produto de uma unidade cultural entre os Estados, mas antes do desejo coletivo da manutenção da ordem, de tal forma que a lógica da anarquia, buscando uma lógica de ordem, substitui a lógica da cultura na constituição das instituições (WILLIAMS, 2006, pp. 13-34), exatamente numa perspetiva contrária à interpretação que Martin Wight dá às instituições em Systems of States, de 1977. 
Para Wight (1977, p. 33), os sistemas de Estados apenas surgem se houver algum "grau de unidade cultural entre os seus membros", já que as instituições surgem como produto da cultura comum entre os membros de um sistema de Estados e os elementos culturais são anteriores à cooperação racional que leva à formação desse sistema. Isto significa que, diferentemente da conceção de Bull, para Wight a lógica da cultura sobrepõe-se à lógica da anarquia no âmbito da constituição histórica das instituições, pois estas resultam da unidade cultural, isto é, de práticas culturalmente afins, e não do desejo dos Estados em manter a ordem internacional (STIVACHTIS, 2003, pp. 137-164).

$\mathrm{Na}$ base desta consideração está o conceito wightiano de sistema de Estados: Estados soberanos que se organizam, no plano internacional, por meio de um sistema através do qual mantêm interações mútuas mais ou menos permanentes, isto é, sistemáticas (WIGHT, 1977, p. 22), sendo certo que estes Estados soberanos são autoridades políticas que não reconhecem poder superior e para as quais o sistema significa, não apenas a reivindicação da sua soberania frente a qualquer autoridade política superior, como também o reconhecimento da validade da mesma reivindicação por parte dos restantes membros, o que representa o reconhecimento mútuo da soberania e independência dos Estados entre si (WIGHT, 1977, p. 23).

Segundo Wight (1977, p. 29), as relações mais ou menos permanentes entre os membros de um sistema de Estados processou-se através de mensageiros, de conferências e instituições internacionais, da linguagem diplomática e do comércio (WIGHT, 1977, pp. 29-33), que acabam por ser as instituições identificadas pelo autor. Ainda que não sejam categorias fixas, pois não aplicáveis a todos os sistemas de Estados que o autor estuda no período histórico que delimita, os mensageiros, as conferências e instituições internacionais, a linguagem diplomática e o comércio acabam por se constituir em instituições, na medida em que surgem como práticas e interações fundamentais e duradouras que os atores estabelecem entre si, dentro de um determinado sistema, dando conteúdo e ordem às relações entre esses atores dentro desse sistema. 
Neste sentido, enquanto Martin Wight fornece uma abordagem histórica, de caráter civilizacional das instituições, Hedley Bull apresenta uma visão mais funcional e teórica do conceito, consolidando o debate sobre as instituições no seio da sociedade internacional da Escola Inglesa (BUZAN, 2006, p. 79).

\section{A Nova Escola Inglesa}

Não obstante a importância da Escola Inglesa no posicionamento terceirista frente ao grande debate que então decorria na teoria das Relações Internacionais, entre idealistas e realistas, com estes sendo também metodologicamente fustigados pelas críticas behavioristas, a verdade é que a Escola Inglesa permaneceu sempre na sombra da Escola Norte-Americana de Relações Internacionais. Na realidade, e como observa Farias Ferreira (2007, p. 35), ao apelidar as Relações Internacionais de ciência social norte-americana, Stanley Hoffmann não tinha, em 1977, em conta a dimensão dos desenvolvimentos acadêmicos da disciplina na Europa após a II Guerra Mundial. Isto contribuiu para que os trabalhos da Escola Inglesa fossem votados a uma invisibilidade, "ora totalmente esquecidos na contabilidade das perspectivas e paradigmas relevantes, ora mergulhados indistintamente na amálgama de um vago realismo anglo-saxónico”.

Jim George (1994, pp. 59-60) chega a referir, a este propósito, que os norte-americanos consideraram irrelevantes a mais abrangente tradição europeia de reflexão filosófica sobre as questões internacionais, o que fez com que muitas questões fundamentais relativas ao internacional nem sequer fossem levantadas. Estas questões não foram, todavia, esquecidas e, na Europa, foram sendo estudadas nas margens da teoria social norte-americana embasada na perspetiva clássica de Grocius, nos teóricos do direito natural e nos fundadores do Direito Internacional em geral. A sua importância reside, fundamentalmente, no desenvolvimento de uma metodologia de pesquisa que contrasta com a tendência quantitativa que crescentemente envolvia os internacionalistas norte-americanos em plena Revolução Behaviorista (FARIAS FERREIRA, 2007, p. 36). 
Ademais, a Escola Inglesa produzia apenas como legado os conceitos de sociedade internacional e instituições internacionais, tornando muito débil a sua agenda de pesquisa, por muito relevantes que tais conceitos fossem para as Relações Internacionais. Para já não falar do fato de a Escola Inglesa se ter tentado desenvolver num momento de predominância do Realismo, que abafava qualquer hipótese de pensamentos alternativos surgirem, sobretudo quando, na década de 1980, Kenneth Waltz (2002 [1979]), lança o Neorrealismo.

Verdade é que, em função de tudo isso, a produção teórica da Escola Inglesa conheceria um interregno durante os anos 1980 e 1990, quando a teoria das Relações Internacionais se voltaria para o debate entre o Neorrealismo e o Institucionalismo Neoliberal. A partir dos anos 1990 começariam a surgir os primeiros trabalhos, mas muito lentamente, como os de James Mayall, em 1990, de Adam Watson, em 1992, de Barry Buzan, em 1993, e de Barkin \& Cronin, em 1993, mas pouco mais viria a ser feito.

É Barry Buzan o grande responsável pela revitalização da Escola Inglesa, após o fim da Guerra Fria, com uma agenda de pesquisa já de acordo com as novas prioridades de investigação das Relações Internacionais. Afinal, Buzan viria a motivar jovens académicos a refletir sobre os conceitos de Wight, Bull e Watson e a aplicá-los à nova realidade internacional. Neste sentido, Buzan traz a Nova Escola Inglesa, caracterizada pelo trabalho feito por aqueles jovens acadêmicos sobre os conceitos clássicos da Escola Inglesa.

Assim, se um traço que marca os autores da Escola Inglesa reside na identificação das possibilidades de evolução da sociedade de Estados e a consequente repartição do sistema, ou sociedade internacional, em fronteiras políticas entre Estados, nas quais também participam as instituições internacionais, a Nova Escola Inglesa traz perspectivas novas sobre a identificação de mais instituições, bem como a sua hierarquização, mudança e evolução, procurando ainda distinguir-lhes novas funções e trabalhando sobre o conceito de regionalização da sociedade internacional. 
Neste contexto, as instituições identificadas por Martin Wight e Hedley Bull são reequacionadas e novas são identificadas, sobretudo pelo trabalho de James Mayall (1990), de K. Holsti (2004) e de Barry Buzan (2004).

Em Nacionalismo e Sociedade Internacional, de 1990, Mayall analisa a influência do nacionalismo sobre a evolução da sociedade internacional, clarificando o desafio que o princípio da autodeterminação nacional dos povos coloca às concepções tradicionais de sociedade internacional e de ordem. Mayall (1990) conclui que o nacionalismo é uma instituição da sociedade internacional no sentido em que transforma a soberania na era moderna.

Do mesmo modo, Mayall (2000, p. 94) identifica o Direito Internacional como uma das principais instituições internacionais, ao referir-se ao mesmo como "a instituição essencial sobre a qual a ideia de sociedade internacional assenta ou cai”, uma visão aliás apoiada por Kratochwil (1989, p. 251), para quem "a ordem internacional legal existe simplesmente por causa do seu papel em definir o jogo das relações internacionais", já que a "sociedade internacional não é meramente regulada pelo Direito Internacional, é também constituída por este" (NARDIN, 1998, p. 20). De salientar, ainda, para Mayall, a diplomacia e a balança de poder enquanto instituições da sociedade internacional (2004, p. 174).

Holsti (2004, p. 18), por seu lado, analisando a mudança nas relações internacionais, refere que as instituições internacionais são os grandes marcadores da mudança na política internacional porque elas compõem "o contexto no qual os jogos da política internacional são jogados. Elas representam os padrões (típicos) de ações e interações dos Estados, as normas, as regras e os princípios que guiam (ou falham em guiar) essas ações e interações e as principais ideias e crenças de uma era histórica. Em segundo lugar, [as instituições internacionais] são críticas quanto à política internacional - as relações entre os Estados - enquanto as mudanças sociológicas globais têm enormes consequências na política entre os Estados. As instituições internacionais contêm as regras essenciais da coexistência entre os Estados e as sociedades", o que significa que, sendo as instituições internacionais a primeira ordem estabelecida, grande parte da mudança social global ocorre no âmbito e, 
por conseguinte, na dependência das regras e normas criadas pelos próprios Estados entre si para regular as suas transações.

Se Holsti segue o conceito de Bull de instituições internacionais (HOLSTI, 2004, p. 20), acrescenta-lhe as ideias e as crenças que escapam ao conceito de Bull, referindo que, além de práticas padronizadas, rotineiras, típicas e recorrentes, as "instituições internacionais baseiam-se, normalmente, em conjuntos coerentes de ideias e/ou crenças que descrevem as necessidades das práticas comuns e referem como determinados objetivos sociais podem ser alcançados através [dessas ideias e crenças]. As ideias referem-se ao entendimento do que "é", tanto de fato como hipoteticamente (...), assim como ao (melhor) estado imaginado das negociações entre os Estados", sendo por isso uma "forma de poder e frequentemente uma composição de outras formas de poder". "As crenças, normas baseadas nas ideias, contêm as justificações para essas ideias e afirmações normativas objetivando a necessidade de determinadas formas de comportamento (normas) e/ou alterações de comportamento". As instituições, assim, "refletem normas, que incluem regras e etiqueta. Elas prescrevem como os atores críticos deveriam comportar-se, sob que condições eles podem fazer determinadas coisas, que tipos de atividades e ações são proscritas e que protocolos e etiquetas deveriam ser observados em determinadas circunstâncias” (HOLSTI, 2004, pp. 21-22).

No entanto, as instituições alteram-se ao longo do tempo, "através de uma variedade de meios e de numerosas fontes, incluindo as ideias e as crenças". Apesar de estarem sujeitas à mudança, as instituições internacionais também são passíveis de sobreviver a grandes transformações. Assim, se a instituição do colonialismo desapareceu, isso ocorreu quando o comércio internacional se transformou, na era moderna, num comportamento que evita a guerra e, portanto, se institucionalizou. Holsti recupera o comércio como instituição, já referida por Wight como uma instituição fundamental da sociedade internacional, assim como a diplomacia, a guerra, o Direito Internacional, a soberania e a territorialidade (BUZAN, 2004, p. 174).

Barry Buzan, considerando a soberania, a territorialidade, a diplomacia, a balança de poderes, a igualdade entre os povos, a desigualdade entre os 
povos, o comércio, o nacionalismo e o meio-ambiente como instituições mestras da sociedade internacional (BUZAN, 2004, pp. 182-183) pondera como instituições derivadas, resultantes das primeiras, a não-intervenção, o Direito Internacional, os direitos humanos, a intervenção humanitária, o colonialismo, o mercado, a autodeterminação, a estabilidade hegemónica, a democracia, dentre muitas outras, cada qual associada a uma instituição mestra (BUZAN, 2004, p. 183).

Ao apontar instituições mestras ou primárias e instituições derivadas ou secundárias da sociedade internacional, Barry Buzan está a hierarquizá-las, na base das duas interpretações que podem ser conferidas às instituições, sendo certo que nenhuma delas se exclui nem nenhum dos dois significados é contestado (BUZAN, 2004, p. 166).

Com efeito, diferentemente das instituições teorizadas pelos regimes internacionais - para cuja teoria as instituições são produto de determinadas sociedades internacionais, em geral liberais, mas sem excluir outros tipos de sociedades, e são na sua maioria racionalmente construídas pelos Estados - as instituições internacionais da Escola Inglesa "são constitutivas, quer dos Estados, quer da sociedade internacional, no sentido em que definem o caráter e o objetivo básicos de qualquer sociedade. Por sociedades de segunda ordem (nas quais os membros são atores coletivos), tais instituições definem as unidades que compõem a sociedade” (BUZAN, 2004, pp. 166-167). Neste sentido, as instituições internacionais refletem algo de muito fundamental e, tal como os factos sociais, estão hierarquicamente estruturados naquilo que a Escola Inglesa chama de "instituições secundárias" (BUZAN, 2004, p. 167).

Sendo o foco central da Escola Inglesa, as instituições primárias ou mestras definem-se como sendo "práticas relativamente fundamentais e duradouras que são evolutivas mais do que desenhadas estaticamente e que são constitutivas dos atores e dos seus padrões de atividade legítima na relação uns com os outros" (BUZAN, 2004, p. 167). "Sendo padrões de práticas partilhadas assente em valores tomados comumente pelos membros das sociedades interestatais, e envolvendo uma mistura de normas, regras e princípios”, as instituições internacionais podem por vezes ver estas práticas e 
estes valores aceites mesmo por atores não-estatais. Mas para serem instituições primárias ou mestras, "as práticas têm de desempenhar um papel constitutivo na relação, quer entre as peças/jogadores, quer entre as regras do jogo". No entanto, conquanto sejam "duradouras, as instituições primárias não são, nem permanentes, nem fixas. Elas seguem tipicamente um padrão histórico de aparecimento, evolução e declínio que acompanha os padrões da vida humana" (BUZAN, 2004, p. 181), o que significa que as mudanças nas práticas dentro das instituições podem ser um sinal de vigor e de adaptação, ou de declínio, o que torna necessário distinguir entre as alterações nas instituições primárias e as alterações nas instituições secundárias (BUZAN, 2004, p. 182).

Já Holsti (2004, p. 24) hierarquiza as instituições da sociedade internacional em instituições fundacionais e instituições procedimentais. As instituições fundacionais definem a sociedade internacional como um tipo específico de arranjo social, com os seus princípios, normas e regras fundamentais, sobre os quais as relações mútuas entre os Estados assentam e se baseiam. Assim surgem formas de ação altamente padronizadas, diferentes de qualquer outra sociedade internacional (HOLSTI, 2004, p. 25).

As instituições procedimentais são “compostas por essas práticas repetitivas, ideias e normas que sublinham e regulam as interações e transações entre os atores individuais". Estas instituições não definem, como as fundacionais, quem são os membros das instituições, no que estas se transformam ou na forma como elas reclamam estatuto ou legitimidade, mas respondem apenas a questões de caráter mais instrumental, como a forma como os atores se comportam uns em relação aos outros na condução do conflito ou das interações pacíficas. Estas instituições procedimentais, ainda que com um caráter secundário relativamente às instituições fundacionais, não deixam de ser importantes por estas razões; elas são importantes na medida em que ajudam a descrever as características essenciais do sistema internacional. Assim pode suceder à instituição procedimental guerra, que pode desaparecer, sem que isso provoque qualquer alteração fundamental nas instituições fundacionais como a soberania ou o Direito Internacional (HOLSTI, 2004, p. 25). 
Neste sentido, se as instituições fundacionais são a soberania, a territorialidade e o Direito Internacional, as instituições procedimentais incluem a diplomacia, o comércio, o colonialismo e a guerra, podendo acrescentar-se o mercado, o sistema monetário internacional e a ajuda externa, já que muitas destas instituições são subcategorias de formas institucionais mais amplas (HOLSTI, 2004, pp. 26-27).

Olhando mais de perto as instituições primárias da sociedade internacional, Buzan considera necessário seguir o caminho aberto por Bull e Mayall no sentido de se compreender a funcionalidade dessas instituições.

Jack Donnelly (2002, pp. 21-23) fez um trabalho preliminar neste âmbito, através de uma lógica funcional construída, tanto sobre o entendimento de Bull de sociedade internacional, quanto sobre os resultados da Escola Inglesa em termos de identificação das instituições internacionais. Assim, Donnelly oferece cinco tipos de funções políticas que são desempenhadas por qualquer sociedade internacional, ao mesmo tempo que a cada função agrega instituições da sociedade internacional já existentes: comunicação e interação (diplomacia e mensageiros), regulação do uso da força (guerra, regras da guerra e práticas específicas que regulam o uso das armas), agregação de interesses e poder (alianças, esferas de influências, instituições governamentais, obrigações feudais e solidariedade religiosa) e alocação e estabelecimento de estatuto (soberania, suserania e império universal).

Mais do que útil para compreender as funções da sociedade internacional, o trabalho de Donnelly parte das sociedades de segunda ordem, daí que seja mais restrito do que a própria tentativa funcional de Bull, que parte de pressupostos para o estabelecimento de funções para qualquer sociedade internacional de primeira ordem.

Tendo em vista esta profusão de estudos sobre os conceitos da Escola Inglesa clássica, a Nova Escola Inglesa também vem questionar se as instituições internacionais seriam afetadas pela mudança de escala geográfica, no caso de se passar a considerar as instituições numa sociedade internacional, não à escala global, mas à escala regional, em função do avanço do regionalismo em várias partes do mundo. 
É assim que a Nova Escola Inglesa vem aplicar os conceitos de instituição e de sociedade às regiões, pois tais conceitos tratam dos valores comuns e das relações permanentes que se estabelecem no âmbito de um grupo de Estados soberanos. Trata-se, pois, de conceitos aplicáveis, tanto ao sistema de Estados que precederam a expansão global da sociedade internacional, como fez Wight, quanto ao plano global, como fez Bull, quanto ainda à escala regional (ZANG, 2014, p. 51), trazendo a geografia de volta à Escola Inglesa (BUZAN, 2004, p. 205).

O próprio conceito de região, trabalhado por alguns acadêmicos, sugere uma aproximação às ideias de sociedade e instituições da Escola Inglesa, já que além da proximidade geográfica, as regiões têm um maior nível de coesão social quando comparadas ao plano global em diferentes áreas (BUZAN, 2012, p. 22). Ademais, um subsistema de Estados geograficamente agrupado tem a sua própria estrutura interna e os seus próprios processos, o que o diferencia da sociedade internacional em que se encontra inserido. Ora esta coesão social e esta capacidade de interação no plano regional permitem que se fale em sociedade, em função da existência de normas, regras, padrões de conduta e instituições regionais (BUZAN, 2012, p. 24), o que leva ao aprofundamento dos estudos sobre as sociedades internacionais regionais.

Neste sentido, o choque entre a lógica da cultura e a lógica da anarquia, apontado por Wight, parece subversivo. As instituições regionais vêm, afinal, reforçar e aprofundar as instituições globais como a diplomacia, o comércio e o Direito Internacional, havendo, antes, uma complementaridade entre a lógica da cultura e a lógica da anarquia. Operando no sistema internacional, a lógica da anarquia levou os Estados à sociedade internacional, enquanto a lógica da cultura acaba por determinar o nível de integração que existe dentro dessa sociedade (RIEMER \& STIVACHTIS, 2002, p. 27).

\section{Conclusões}

As abordagens internacionalistas de Hedley Bull (2002) e de Martin Wight (1977), no âmbito da terceira via da Escola Inglesa, ainda que tenham produzido como resultados os conceitos de sociedade internacional e de instituições internacionais, fundamentais para a evolução da disciplina das 
Relações Internacionais, assentam numa base profundamente distinta. Enquanto o conceito de sociedade internacional de Bull busca a ordem procura substituir o caos pela ordem através da criação de laços que unam os Estados e que os levem, voluntariamente, a criar princípios, normas, regras e padrões comuns de comportamento para cumprirem voluntariamente, em nome da ordem (BULL, 2002, pp. 8, 13) - o conceito de Wight assenta na cultura. Somente quando existe uma estreita ligação cultural entre os Estados é que se torna possível criar uma sociedade internacional com as suas instituições internacionais (1977, p. 33).

Não obstante esta distinção, a Escola Inglesa firmou, de alguma forma, o seu lugar na Europa, todavia nunca chegou a deter adeptos suficientes para fazer frente à Escola Norte-Americana de Relações Internacionais, face à qual esteve sempre marginalizada, chegando as Relações Internacionais a ser mesmo consideradas uma ciência social norte-americana, enquanto os estudos da Escola Inglesa eram levados a efeitos à margem, através de uma metodologia que divergia da metodologia behaviorista dos estudos norte-americanos. Ademais, não obstante a solidez dos estudos conduzidos pela Escola Inglesa, a sua agenda de pesquisa conseguiu apenas, como resultados concretos, obter a conceitualização de sociedade internacional e de instituições internacionais. Por outro lado, e fundamentalmente, os autores da Escola Inglesa trabalhavam num período de dominância, ainda que menor, porém considerável, do Realismo e da Guerra Fria, que abafava todas as hipóteses de surgimento de outros pensamentos, razão pela qual a Escola viria a entrar em período de decadência nas décadas de 1980-1990, até que o derrube do muro de Berlim e a dissolução da URSS abrissem espaço a novas e velhas formas de pensamento. Responde-se, desta forma, à pergunta de partida desta pesquisa, objetivo essencial da mesma e, por conseguinte, deste capítulo.

Ademais, verifica-se, pelo exposto em todo o capítulo, que, se a Escola Inglesa clássica não veio fazer nenhuma hierarquia das instituições - pese embora a maior importância conferida por Bull à soberania, dentre as suas cinco instituições, em virtude de corresponder ao princípio ordenador da sociedade internacional - a Nova Escola Inglesa vem hierarquizar as várias (e novas) instituições que identifica. Do mesmo modo, enquanto os novos 
estudos apresentam uma perspetiva evolutiva das instituições da sociedade internacional, os textos clássicos de Bull e Wight apresentam uma visão estática das instituições da sociedade internacional, já que qualquer evolução das mesmas não é considerada como possível. Nos novos trabalhos, ao contrário, as instituições aparecem como evolutivas, sujeitas ao surgimento, evolução e declínio (BUZAN, 2004, p. 182).

Desta forma, James Mayall (1990) analisa a influência do nacionalismo sobre a evolução da sociedade internacional, concluindo que esta é uma nova instituição internacional no sentido em que transforma a soberania na era moderna. Kratochwill (1989, p. 251) e Nardin (1998, p. 20) consideram, por sua via, que a ordem internacional legal existe em função do seu papel definidor do jogo das relações internacionais, já que a sociedade internacional não é apenas regulada pelo Direito Internacional, é também constituída por este.

Se Holsti (2004, p. 20), por seu lado, segue o conceito de Bull de instituição internacional, acrescenta-lhe as práticas padronizadas, rotineiras, típicas e recorrentes, sendo certo que tais instituições internacionais se alteram ao longo do tempo em função de numerosos meios e fontes, que incluem as ideias e as crenças. Para o autor $(2004$, p. 26), as mudanças nas instituições da sociedade internacional, seja por transformação, inovação ou obsolescência, alteram a configuração de toda a sociedade internacional.

Barry Buzan (2004, pp. 182-183) hierarquiza as instituições internacionais em instituições mestras e instituições derivadas. Já Holsti (2004, p. 24) hierarquiza-as em instituições fundacionais e instituições procedimentais, sendo que as primeiras definem a sociedade internacional como um tipo específico de arranjo social, com os seus princípios, normas e regras fundamentais, sobre os quais assentam as interações entre os Estados. Neste sentido, fica claro ter-se alcançado o primeiro objetivo desta investigação, que procurava avaliar as novas perspectivas e instituições, sua hierarquização, mudança e evolução, elaborada por parte da Nova Escola Inglesa. Simultaneamente, comprova-se a primeira hipótese de trabalho, em ligação direta com este objetivo. 
Jack Donelly (2002, pp. 21-23) trabalha, por seu lado, sobre as funções da sociedade internacional, indicando-lhe cinco novas funções, a saber: comunicação e interação, regulação do uso da força, agregação dos interesses e poder e alocação e estabelecimento de estatuto, conforme analisado ao longo do capítulo.

Finalmente, e tendo em consideração o avanço dos processos de regionalização um pouco por todo o mundo, a Nova Escola Inglesa questiona se as instituições internacionais seriam afetadas pela alteração da escala geográfica, chegando à conclusão que não - e que, por conseguinte, os conceitos de sociedade internacional e de instituições internacionais podem ser aplicáveis à escala regional (ZANG, 2014, p. 51). Assim se alcança o segundo objetivo proposto e se valida a segunda hipótese de trabalho.

Na verdade, a coesão social que existe numa região é maior do que a que existe no plano internacional, de modo que a interação no plano regional permite que se fale em sociedade, até pela existência de normas, regras, padrões comuns de comportamento e instituições regionais (BUZAN, 2012, p. 24).

Interessante notar, ainda, que, tal como os realistas, a Escola Inglesa acredita na importância da anarquia, da guerra e da balança de poderes. Mas apenas enquanto ideias que moldam a prática política internacional e não enquanto leis fundamentais do sistema internacional ou fenômenos imutáveis enraizados na estrutura do sistema internacional (DOUGHERTY \& PFALTZGRAFF, 2003, p. 216). Isto porque, além do sistema internacional, pode existir a sociedade internacional, ainda que um sistema internacional possa existir sem a existência de uma sociedade internacional (DOUGHERTY \& PFALTZGRAFF, 2003, p. 153). O estudo da sociedade internacional é, como ficou claro, o ponto de partida da Escola Inglesa, sendo certo que as sociedades, em termos gerais, são "mecanismos cooperativos para garantir vantagens mútuas aos seus membros" (DUNNE, 1998, p. 10). Assim, uma sociedade internacional existe enquanto tal porque os agentes dos Estados interagem em nome dos seus Estados concebidos como membros dessa sociedade, o que significa que a sociedade internacional é uma realidade socialmente construída. A sociedade internacional parte da premissa da 
igualdade soberana dos Estados, mas inclui uma estrutura com princípios legais e normas ou padrões de conduta (DOUGHERTY \& PFALTZGRAFF, 2003, pp. 153-154).

Neste sentido, as estruturas moldam as normas de conduta que governam a sociedade, de tal modo que qualquer sociedade internacional é caracterizada por padrões normativos ou regras de conduta partilhados (DOUGHERTY \& PFALTZGRAFF, 2003, p. 154). Nesta base, a Escola Inglesa viria a influenciar profundamente e a estar na base do pensamento dos teóricos construtivistas, para os quais a sociedade internacional é fundada em estruturas intersubjetivas que são, elas próprias, resultado de ideias e crenças que produzem condutas baseadas em regras e valores comumente aceites e firmemente arraigados nas instituições e práticas internacionais, alcançando-se desta forma o último objetivo desta pesquisa e validando-se, por conseguinte, a terceira e última hipótese.

\section{Referências}

BROWN,C.; AINLEY,K. (2009) Compreender as Relações Internacionais. Gradiva: Lisboa.

BULL, H. (2002 [1977]) A Sociedade Anárquica. Imprensa Oficial do EstadoUnB-IPRI: São Paulo.

BULL, H. (1966) «The Grotian Conception of International Society». Diplomatic Investigations. George Allen \& Unwin: London.

BUZAN, B. (2012) «How Regions were Made and the Legacies for World Politics: an English School Reconnaissance». International Relations Theory and Regional Transformation. Pp. 22-48. Cambridge University Press: Cambridge.

BUZAN, B. (2006) «Rethinking Hedley Bull on the Institutions of International Society». The Anarchical Society in a Globalizing World. Pp. 7596. Palgrave Macmillan: New York.

BUZAN, B. (2004) From International to World Society? English School Theory and the Social Structure of Globalization. Cambridge University Press: Cambridge.

BUZAN, B. (2001) «The English School: an Underexploited Resource». IR Review of International Studies, Vol. 27, N. 3, 2001, pp. 471-488.

BUZAN, B. ; GONZALEZ-PELAEZ, A. (eds.) (2009) International Society and the Middle East: English School Theory at the Regional Level. Palgrave Macmillan: New York. 
DONNELLY, J. (2002) The Constitutional Structure of Ancient Greek International Society, paper presented at BISA Conference, London, December, 2002, 39p.

DOUGHERTY, J. ; PFALTZGRAFF, R. (2003) Relações Internacionais - As Teorias em Confronto. Gradiva: Lisboa.

DUNNE, T. (1998) Inventing International Society: A History of the English School. Saint Martin`s Press: New York.

FARIAS FERREIRA, M. (2007) Cristãos e Pimenta - a Via Média na Teoria das Relações Internacionais de Adriano Moreira. Almedina: Coimbra.

GEORGE, J. (1994) Discourses of Global Politics: a Critical (Re)Introduction to International Relations. Boulder: Lynne Rienner.

HOLSTI, K.J. (2004) Taming the Sovereigns: Institutional Change in International Politics. Cambridge University Press: Cambridge.

KINGSBURY, B. (1999) «Grotius, Law, and Moral Scepticism: Theory and Practice in the Thought of Hedley Bull». Classical Theories of International Relations. Pp. 42-70. St. Martin`s Press: New York.

KRATOCHWIL, F. (1989) Rules, Norms and Decisions: On the Conditions of Practical and Legal Reasoning in International Relations and Domestic Affairs. Cambridge University Press: Cambridge.

MAYALL, J. (2000) World Politics: Progress and Its Limits. Polity Press: Maiden, USA.

MAYALL, J. (1990) Nationalism in International Society. Cambridge University Press: Cambridge.

NARDIN, T. (1998); «Legal Positivism as a Theory of International Society» in International Society: Diverse Ethical Perspectives. Pp. 17-35. Princeton University Press: Princeton.

RIEMER, A. K. \& STIVACHTIS, Y. A. (2002) «European Union's Enlargement, the English School and the Expansion of Regional International Societies». Understanding EU's Mediterranean Enlargement: The English School and the Expansion of Regional International Societies. Peter Lang: Frankfurt.

STIVACHTIS, Y. A. (2003) «Europe and the Growth of International Society: Anarchy More than Culture». Revista Global Dialogue, Vol. 5, N. 3-4, 2003, pp. 137-164.

WALTZ, K. (2002 [1979]); Teoria das Relações Internacionais. Gradiva: Lisboa.

WIGHT, M. (1985 [1946]) A Política do Poder. Editora Universidade de Brasília: Brasília DF.

WIGHT, M. (1977) Systems of States. Leicester University Press: Leicester. 
WILLIAMS, J. (2006) «Order and Society». The Anarchical Society in a Globalized World. Pp. 13-34. Palgrave MacMillan: New York.

ZANG, Y. (2014) «Towards a Regional International Society: Making Sense of Regionalism in East Asia». Regions in International Society: The English School at the Sub-Global Level. Mazarik University, 2014, pp. 45-67. [Consultado em Dezembro de 2015] Disponível em www.globalpolitics.cz/en. 